\title{
Numerical analysis of suction embedded plate anchors in structured clay
}

\author{
T. S. Charlton ${ }^{\mathrm{a}}$, M. Rouainia ${ }^{\mathrm{a}}$, A. Gens ${ }^{\mathrm{b}}$ \\ ${ }^{a}$ Newcastle University, School of Civil Engineering and Geosciences, Newcastle upon Tyne NE1 7RU, UK \\ ${ }^{b}$ Universitat Politècnica de Catalunya, BarcelonaTech, Campus Norte UPC, 08034 Barcelona, Spain
}

\begin{abstract}
As offshore energy developments move towards deeper water, moored floating production facilities are increasingly preferred to fixed structures. Anchoring systems are therefore of great interest to engineers working on deep water developments. Suction embedded plate anchors (SEPLAs) are rapidly becoming a popular solution, possessing a more accurate and predictable installation process compared to traditional alternatives. In this paper, finite element analysis has been conducted to evaluate the ultimate pullout capacity of SEPLAs in a range of postkeying configurations. Previous numerical studies of anchor pullout capacity have generally treated the soil as an elastic-perfectly plastic medium. However, the mechanical behaviour of natural clays is affected by inter-particle bonding, or structure, which cannot be accounted for using simple elasto-plastic models. Here, a novel application of an advanced constitutive model formulated within the kinematic hardening framework is used to accurately predict the degradation of structure as an anchor embedded in a natural soft clay deposit is loaded to its pullout capacity. In comparison with an idealised, non-softening clay, the degradation of clay structure due to plastic strains in the soil mass results in a lower pullout capacity factor, a quantity commonly used in design, and a more complex load-displacement relationship. It can be concluded that clay structure has an important effect on the pullout behaviour of plate anchors.
\end{abstract}




\section{Introduction}

In recent decades the global demand for energy has increased rapidly and this trend is predicted to continue into the future [1]. Offshore oil and gas reserves have been a mainstay of energy production around the world. However, as the most accessible resources in shallow coastal waters are depleted, the attention of energy producers is moving further offshore [2]. Energy resources requiring installations in water depths of over $2000 \mathrm{~m}$ are becoming economically viable and the engineering challenges of deep water developments are therefore of great importance.

As water depths increase rigid structures that are fixed to the seabed, such as jackup units, jacket platforms and gravity platforms, become impractical. Instead, moored floating facilities are preferred. An anchoring system tethers the structure to the seabed, with the amount of free movement of the facility being controlled by the mooring arrangement. The primary goal of the anchor is to resist the combined vertical and horizontal pullout loads that the floating facility is

subjected to in the offshore environment.

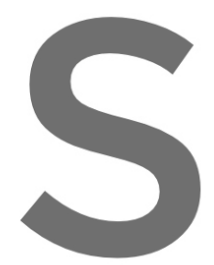

Suction embedded plate anchors (SEPLAs) are designed to drag embedded anchors soil mass in front of th which operate accordi g to the same 1
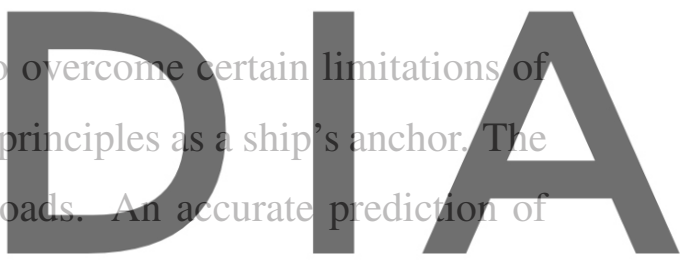

holding capacity is difficult as embedment depth of drag-in anchors is hard to predict. SEPLAs

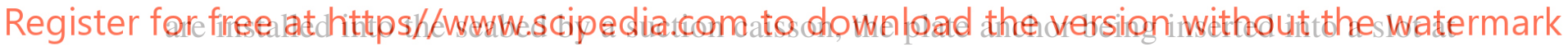

the base of the caisson during penetration. The depth and location of the installed anchor are consequently known to a high degree of accuracy. Using the plate anchor rather than the suction caisson itself for anchoring is significantly less expensive [3]. Following installation, the plate anchor is keyed into the soil through loading of the anchor chain and rotates from a vertical orientation to a direction normal to the applied load if the anchor is symmetrically loaded.

The problem of anchor pullout capacity in undrained clay has been studied by various researchers. For horizontal anchors, Vesic [4] proposed an analytical solution for pullout capacity based on cavity expansion theory in a rigid-plastic material; this approach provides reasonable results for shallow anchors in soft clays. Das [5] presented a more versatile approach for the estimation of pullout capacity of shallow and deep horizontal anchors, with an empirical expression derived from model tests.

Rowe and Davis [6] undertook both an experimental and numerical investigation of horizontal and vertical plate anchor capacity in clay. Finite element analysis was used to predict pullout factor values for a range of anchor configurations and soil types, and results were found to agree 
well with model tests. The study considered an idealised clay which deforms according to the Tresca criterion. A practical definition of failure was adopted, with the failure load being taken as the load causing a displacement four times that of an elastic analysis. This was due to the extent of plastic deformation observed before a well-defined collapse load could be obtained. Merifield et al. [7] used a finite element formulation of upper and lower bound theorems from limit analysis to analyse a similar problem. Results provide a bracket for the true collapse load, and were shown to compare favourably with previous laboratory work.

For SEPLAs, the keying process undertaken after insertion of the anchor by suction caisson leads to rotation and loss of embedment. This was observed in field tests reported by Wilde et al. [3] and has been a recent topic of research [e.g. 8, 9]. The capacity of plate anchors at a range of inclination angles is therefore of interest. Limited empirical research has been undertaken, for example the study by Das and Puri [10] tested a model square anchor at several inclination angles to obtain an empirical expression for pullout capacity. Meyerhof [11] also presented a closed-form expression for inclined strip and square anchors in frictional soils. Merifield et

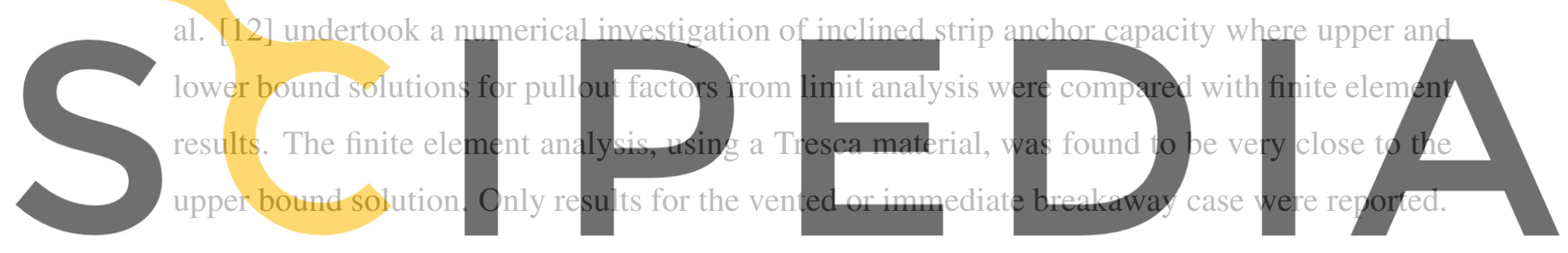

Recently, a range of further studies applying finite element analysis have been carried out. Register for free at httosflwww. scipedia, com to download the version without the watermark

range of inclination angles and considered a variety of soil conditions. The effect of an inhomogeneous strength profile on the pullout capacity of a square anchor was extensively analysed by Tho et al. [14] using a three-dimensional large deformation finite element formulation. Other examples of finite element studies include Wang et al. [15] and Fahmy et al. [16].

In these cases, the soil was described as a simple elastic-perfectly plastic material. This assumption may be unsuitable for describing natural clays, which often show inter-particle bonding, or structure, that can significantly affect mechanical behaviour [17]. Load-displacement curves show rapid post-peak softening as structure degrades with increasing soil deformation. As an extreme example, the highly sensitive quick clays of Scandinavia [18] demonstrate the impact of the loss of natural structure during soil deformation. In this paper, an advanced soil constitutive model will be used in a finite element analysis of the ultimate pullout capacity of a SEPLA in an undrained structured clay. Plate anchor capacity will be evaluated in a range of post-keying inclinations. This will allow an assessment of the effect of soil structure on pullout capacity, and the subsequent implications for design. In addition, the localised degradation of 
structure in the soil mass during the deformation process may be observed and related to the failure mechanism.

\section{Plate anchor capacity}

\subsection{Problem outline}

This study considers a strip anchor and the layout and notation are shown in Fig. 1. A SEPLA, in its post-keying state, may be rotated at any angle depending on the direction of the applied load and the configuration of the plate anchor, including factors such as offset of the padeye from a central position. Here, the pullout load is considered to act at the midpoint and in a direction perpendicular to the longitudinal axis of the anchor. The inclination angle, $\beta$, is measured from the horizontal. The embedment depth of the anchor is non-dimensionalised by considering the $H / B$ ratio.

Pullout behaviour of an anchor is affected by the strength of the interface between the anchor

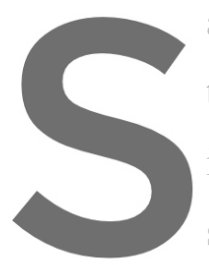
and surrounding soil. to a purlout load. immediate breakaway soil, and the no breakaway 'attached' condition w
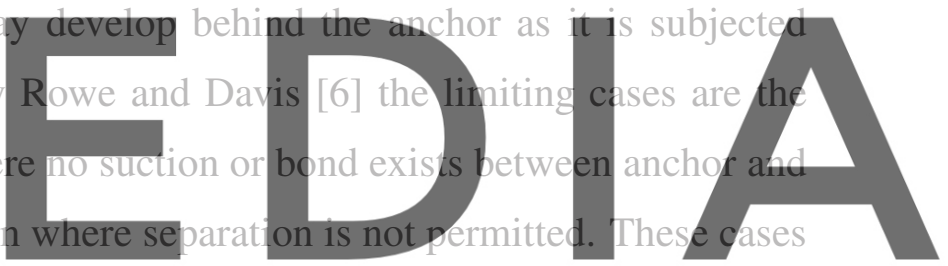

form a lower and upper bound, respectively, for the true pullout capacity, as the developed Register for free at https//www. scipedia.com to download the version without the watermark suction or bond between anchor and plate must lie between the two extremes. A distinction is

also made between shallow and deep anchors [7]. For a shallow anchor, the failure mechanism involves a block of soil being lifted upwards with the shear planes extending to the ground surface. However, at a certain critical embedment depth the shear zone becomes localised around the anchor. This flow-around mechanism no longer reaches the surface and the anchor is classified as deep.

\subsection{Pullout capacity factor}

In an undrained clay, the primary design concern is the ultimate pullout capacity of the plate anchor. This is generally expressed as a pullout capacity factor:

$$
N_{c}=\frac{Q_{u}}{A s_{u}}
$$

where $Q_{u}$ is the ultimate pullout load, $A$ is the plate area and $s_{u}$ the undrained shear strength. This approach is followed by current design codes [e.g. 19] for capacity assessment. If the 

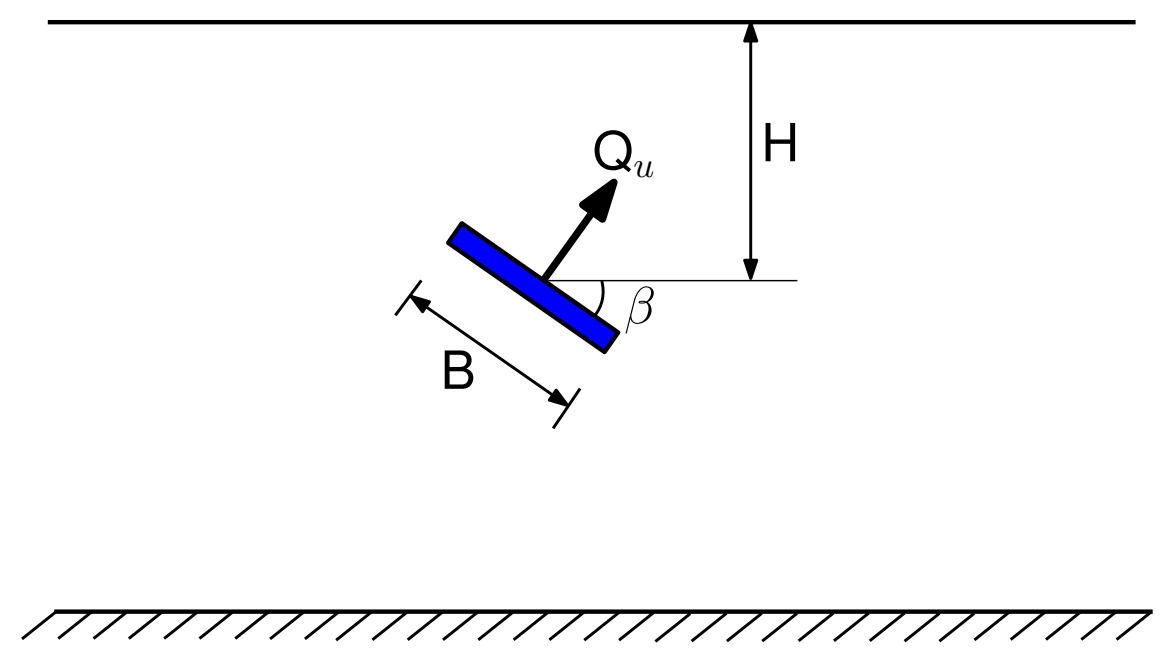

Figure 1: Schematic of plate anchor pullout scenario and sign convention.

anchor is installed in a soil with an undrained shear strength that increases with depth, the pullout capacity factor may be obtained as:

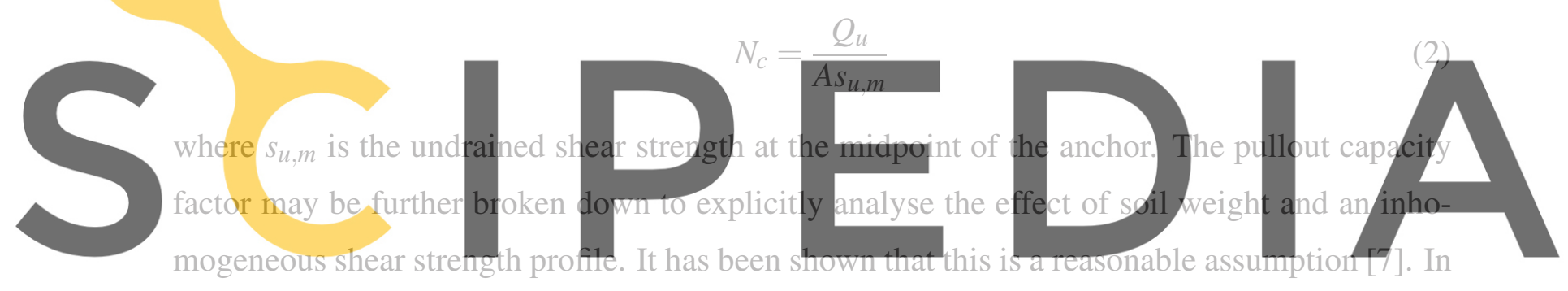

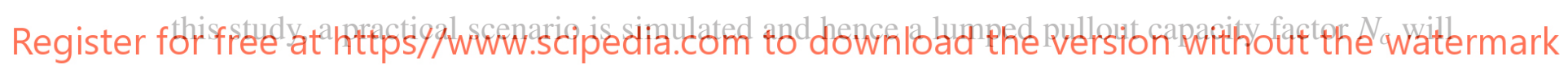

be calculated with soil weight and inhomogeneous shear strength considered simultaneously.

\section{Constitutive model}

The kinematic hardening structure model (KHSM) developed by Rouainia and Muir Wood [20] is used to describe the effect of clay structure on anchor uplift capacity. The KHSM incorporates soil structure by observing that with total loss of structure the soil behaves as a remoulded material. Hence, the framework is built upon the classic modified Cam-clay (MCC) model [21]. The KHSM extension is based on the introduction of a kinematic hardening bubble, which contains the elastic behaviour, and an outer structure surface to describe the state and effect of soil structure.

The essential feature of the KHSM is the degradation of soil structure as plastic strain is accumulated and hence this will be detailed here. The relative size of the structure surface to the reference MCC surface describes the degree of structure, $r$, of the clay. The degradation of structure is modelled by a destructuration law: 


$$
r=1+\left(r_{0}-1\right) \exp \left(\frac{-k \varepsilon_{d}}{\lambda^{*}-\kappa^{*}}\right)
$$

where $r_{0}$ is the initial degree of structure, $k$ controls the rate of destructuration with plastic 'damage' strain, $\varepsilon_{d}, \lambda^{*}$ is the slope of the normal compression line and $\kappa^{*}$ is the slope of the swelling line in a volumetric strain-logarithmic mean stress plot. It can be seen that $r$ is a monotonically decreasing function of the damage strain. The clay is remoulded with no structure when $r=1$. The damage strain itself is calculated from the components of plastic strain by a relationship between the strain rates:

$$
\dot{\varepsilon}_{d}=\left[(1-A) \dot{\varepsilon}_{v}^{p 2}+A \dot{\varepsilon}_{q}^{p 2}\right]^{1 / 2}
$$

where $\varepsilon_{v}^{p}$ is plastic volumetric strain and $\varepsilon_{q}^{p}$ is plastic shear strain. A is a dimensionless parameter that determines how $\varepsilon_{v}^{p}$ and $\varepsilon_{q}^{p}$ contribute to the damage strain, and thus the destructuration of the clay.
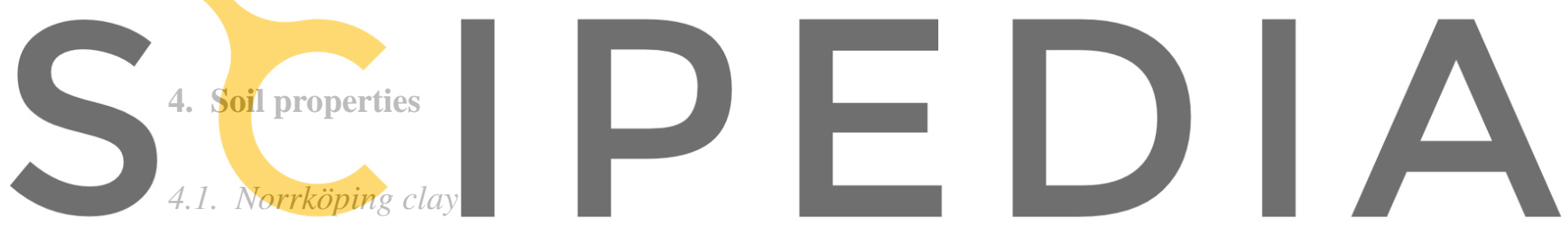

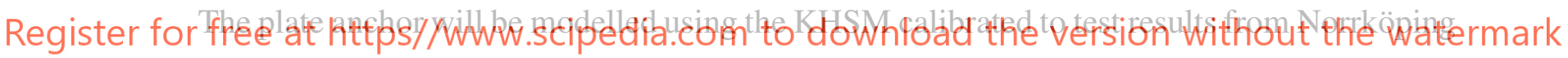

clay. The calibration procedure was undertaken and reported by Rouainia and Muir Wood [20].

The Norrköping clay is inorganic and of low sensitivity, with a plasticity index of 0.43 and a liquidity index of 1.2. Clay and silt content is $62 \%$ and $36 \%$ respectively. The calibrated parameters are given in Table 1. The initial degree of structure of the Norrköping clay is 1.75. An effective unit weight $\left(\gamma^{\prime}\right)$ of $10 \mathrm{kN} / \mathrm{m}^{3}$ is considered throughout and the initial stress conditions are generated by $K_{0}$ consolidation, with $K_{0}$ equal to 0.5 .

\subsection{Undrained shear strength profile}

The KHSM is implemented as a user defined model in the finite element code Plaxis 2D, which is used for all numerical simulations in this study. Undrained shear strength is not an input parameter in the KHSM, but a profile of $s_{u}$ with depth is needed to determine the pullout capacity factor of a plate anchor. Plane strain shear tests were therefore simulated.

Fig. 2 presents results from an undrained plane strain compression test on a $K_{0}$ consolidated sample at $20 \mathrm{~m}$ depth. The effect of structure on the mechanical behaviour of the clay during the 
Table 1: Soil parameters for Norrköping clay.

\begin{tabular}{|l|r|}
\hline Material property & Value \\
\hline \hline Slope of swelling line, $k^{*}$ & 0.0297 \\
Slope of normal compression line, $\lambda^{*}$ & 0.252 \\
Poisson's ratio, $v$ & 0.22 \\
Critical state stress ratio, $M$ & 1.35 \\
Ratio of size of bubble and reference surface, $R$ & 0.145 \\
Stiffness interpolation parameter, $B$ & 1.98 \\
Stiffness interpolation exponent, $\psi$ & 1.55 \\
Initial degree of structure, $r_{0}$ & 1.75 \\
Destructuration strain parameter, $A$ & 0.494 \\
Destructuration parameter, $k$ & 4.16 \\
Anisotropy of initial structure, $\eta_{0}$ & 0 \\
\hline
\end{tabular}

test is demonstrated in Fig. 2a. A clear peak strength is observed before softening behaviour occurs due to degradation of the structure with continuing strain. Eventually the behaviour of the structured clay matches that of the MCC model, obtained by setting parameters $r_{0}$ and $R$ equal to 1 in the KHSM. This case represents remoulded clay as no structure exists in the model,
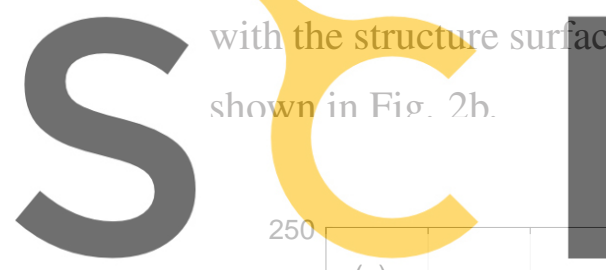

(a)
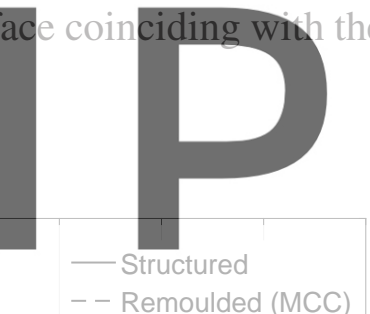

- - Remoulded (MCC)

Register for free at https//www.scipedia.com to

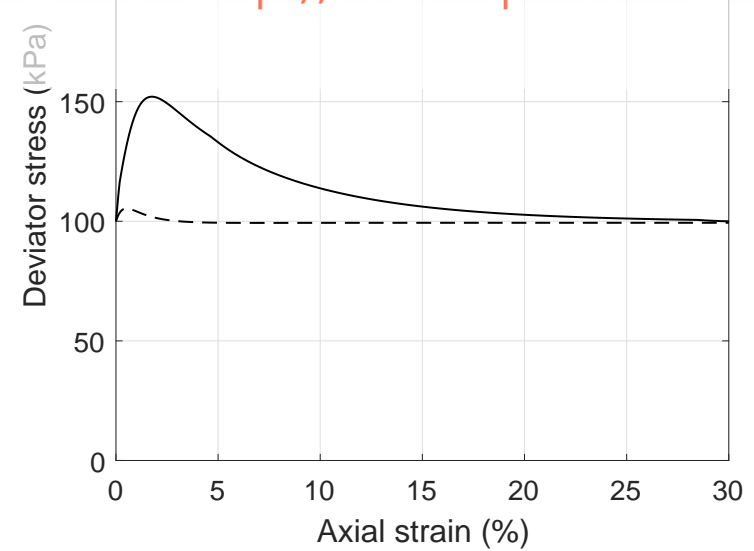

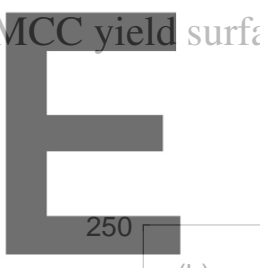

(b)

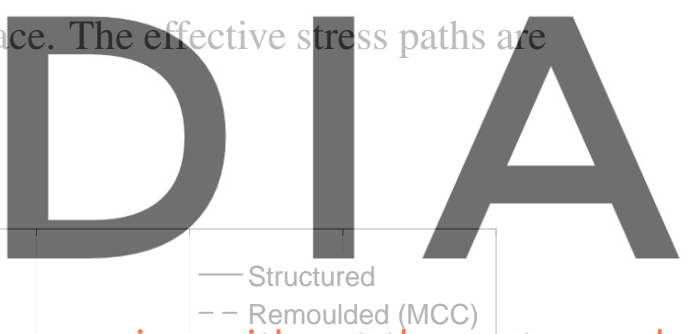

- - Remoulded (MCC)

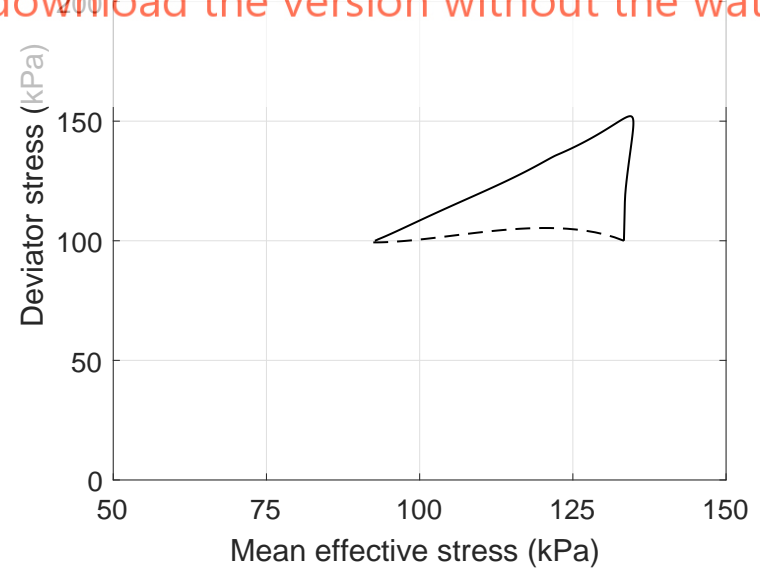

Figure 2: Undrained plane strain compression test using KHSM model: (a) Deviator stress-axial strain response and (b) effective stress path.

The undrained shear strength of the clay is determined from a series of undrained plane strain compression tests using the in-situ $K_{0}$ consolidated stress state at different depths. The resulting $s_{u}$ profiles of both structured and remoulded clay, calculated from the peak strengths exhibited during the tests, are shown in Fig. 3. It may be seen that $s_{u}$ increases linearly with depth. 
For the default structured clay parameters in Table 1, the strength increases at a gradient of $4.30 \mathrm{kPa} / \mathrm{m}$ while in the remoulded clay the gradient is $2.94 \mathrm{kPa} / \mathrm{m}$. A normally consolidated clay is considered as this is typical of seabed sediments in many areas of interest for offshore development. The sensitivity of the Norrköping clay is 1.46; this may be somewhat lower than the sensitivity of marine clays where SEPLAs would typically be deployed but it should be noted that the KHSM can easily be calibrated to clays of higher sensitivity.
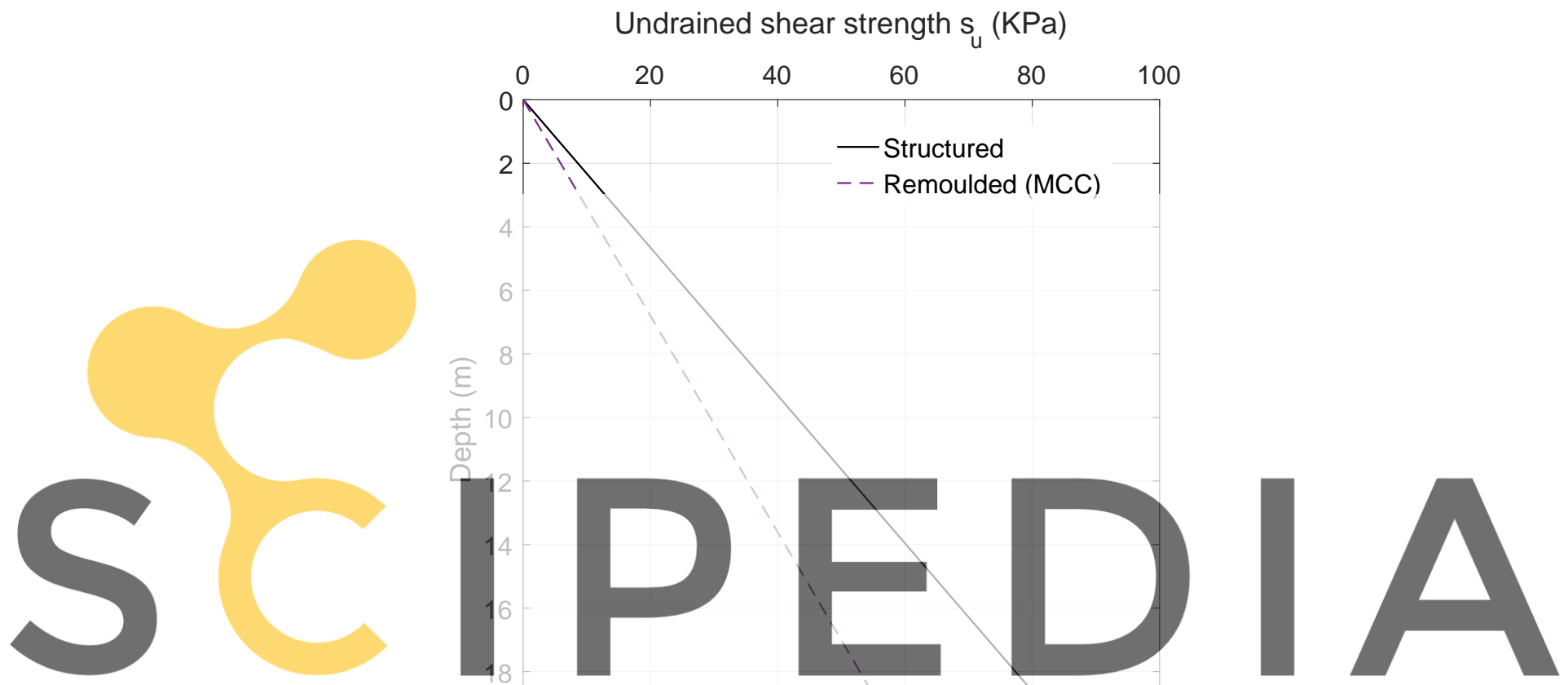

Register for free at https//www'scipedia.com to download the version without the watermark

Figure 3: Profiles of undrained shear strength.

\section{Model set up}

\subsection{Finite element model}

A plane strain finite element model was created in Plaxis using 15 node triangular elements, as shown in Fig. 4. The model boundaries are fixed along the base and horizontal translation is prevented at the sides. Results indicated that a model of size $25 B \times 20 B$ (with $B=2 \mathrm{~m}$ ) was sufficient to avoid boundary effects on the ultimate pullout load. The anchor itself is modelled by a plate element of very high stiffness. The analysis is displacement-based to ensure a rigid plate response. Soil-structure interaction is described with the aid of an interface element. An interface is applied along the anchor base to model the vented and attached conditions and is extended beyond the end of the anchor to avoid stress irregularities at the corner points. In the vented condition, a very low stiffness is applied to simulate the lack of bonding or suction 
between plate and soil. In all cases, a smooth anchor is considered. Whilst not realistic, this will provide a conservative solution.
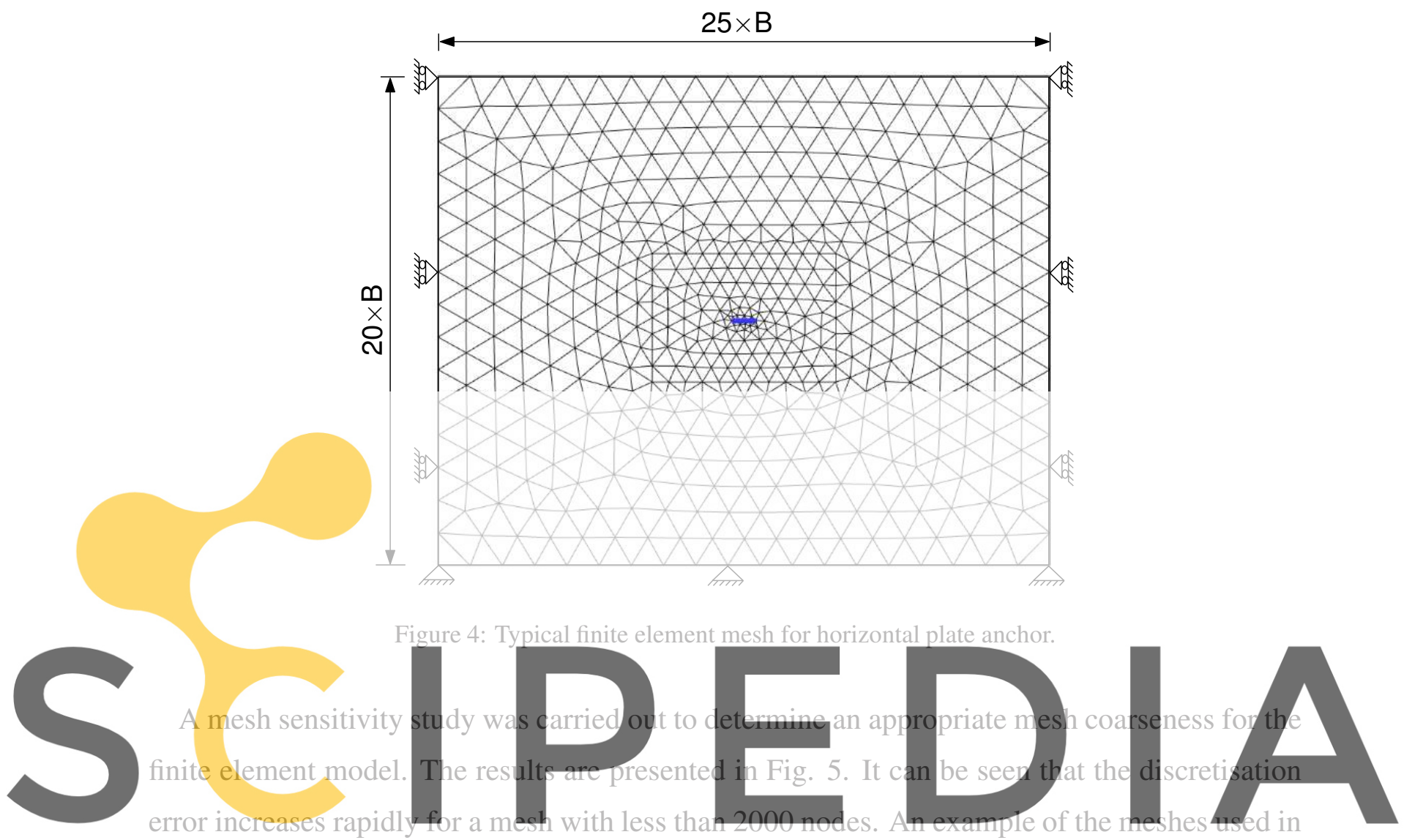

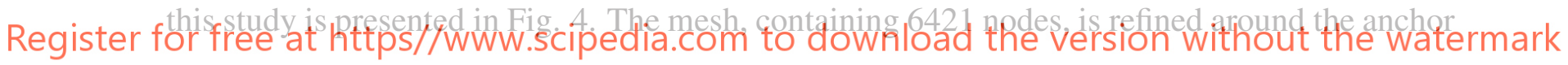
to improve accuracy in the failure zone.

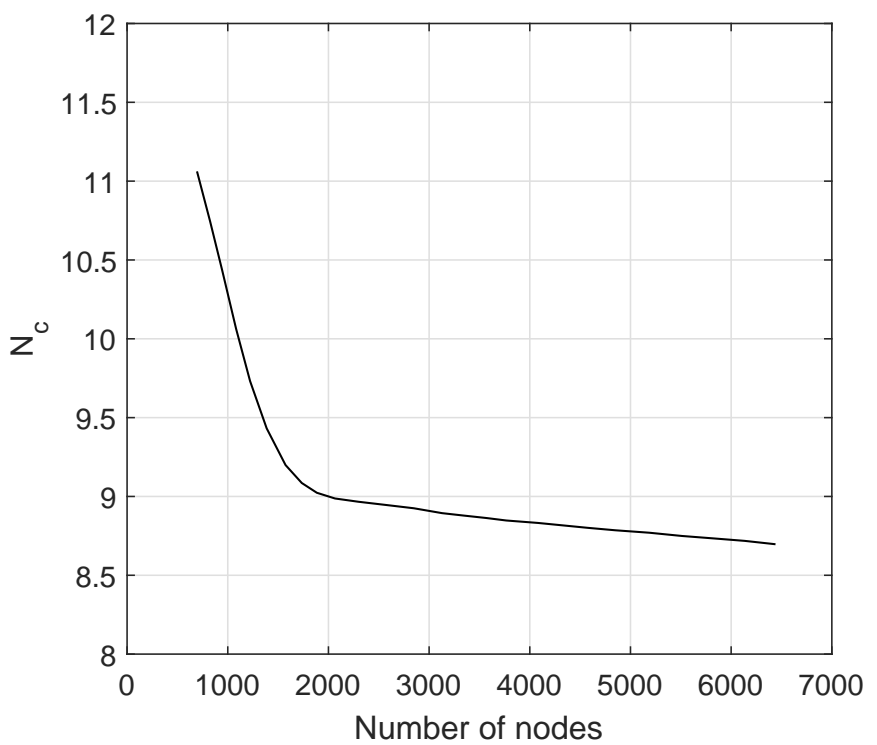

Figure 5: Mesh sensitivity 
The ultimate pullout capacities are obtained for specific embedment depths and the position of the mesh is not updated throughout the analysis. The effect of geometric non-linearity as the anchor is pulled out of the soil is beyond the scope of this paper. However, previous small-strain finite element studies [e.g. 6, 13] have given adequate solutions for the ultimate pullout capacity when compared with results of laboratory experiments and limit analysis formulations.

\subsection{Selection of failure criterion}

Yu et al. [13] report that in attached conditions the ultimate load is reached quickly, requiring only a relatively small displacement. For vented anchors the ultimate load will not be reached until the failure mechanism reaches the surface; if the anchor is deeply-embedded for this to occur the soil deformation will be extremely high. It was for this reason that Rowe and Davis [6] adopted a practical failure criterion, based on an assessment of elastic displacement. Here, a similar approach is taken in vented cases primarily for numerical expediency. Based on preliminary results, a displacement of $0.5 B(1.0 \mathrm{~m})$ is selected as the failure criterion. It is worth

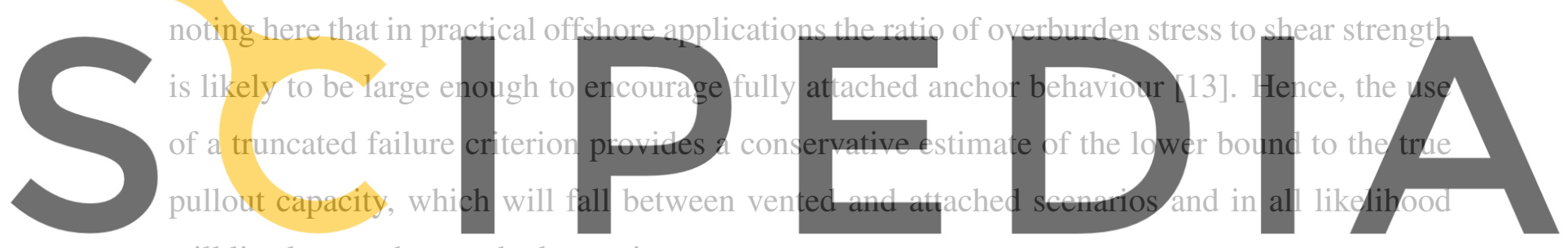

will lie close to the attached capacity.

Register for free at https//www.scipedia.com to download the version without the watermark

6. Results and discussion

\subsection{Analysis of the effect of structure on pullout capacity}

\subsubsection{Load-displacement behaviour}

The effect of clay structure on anchor pullout capacity may be demonstrated by varying the degree of initial structure and the rate of destructuration, which are controlled by parameters $r_{0}$ and $k$ respectively. The parametric study is undertaken on a deep anchor embedded at $H / B=10$ $(20 \mathrm{~m})$; the default parameter values are those given in Table 1 unless otherwise stated. For each set of parameters, the peak undrained shear strength is determined at anchor embedment depth (20m) by a plane strain compression test and used for normalisation of the pullout force. Values of initial structure of 1, 1.75, 2.5 and 3 are considered, corresponding to sensitivities of $1,1.46$, 1.82 and 2. It should be noted that in the case $r_{0}=1$, an MCC model is used with $R=1$, as this enables comparison with a conventional soil model. The rate of destructuration is varied from 
$k=0$, when structure does not degrade with plastic strain (see Eq. 3), to the calibrated value of $k=4.16$.

Fig. 6a shows the development of the pullout force of an attached anchor with increasing total displacement $(u)$. In attached conditions the structured clay $\left(r_{0}>1\right)$ shows a peak strength before softening occurs as plastic strains develop and structure is lost. It is clear that a greater degree of initial structure results in a higher peak. In the remoulded clay $\left(r_{0}=1\right)$ the load increases monotonically until an ultimate pullout force is reached. This ultimate force is equal to that of the structured cases at large displacements due to the structured clay being completely remoulded along the failure planes. The post-peak softening of the structured clays occurs at a similar rate as the calibrated $k$ value is used in each simulation.

Fig. $6 \mathrm{~b}$ presents normalised load-displacement curves with the pullout capacity factor $N_{c}$ calculated using Eq. 2 and the total displacement normalised by the anchor width. It can be seen that when the degradation of clay structure is taken into account the value of the pullout capacity factor is significantly reduced, from a maximum 12.0 in the remoulded clay to 8.7 in the calibrated Norrköping clay. Furthermore, the pullout capacity factor appears to reduce as the degree of initial structure is increased.

The rate of destructuration also has an important effect on anchor pullout capacity. Fig. 6c shows that if structure remains constant $(k=0)$, no softening occurs and the pullout force increases monotonically. When structure degrades with plastic strain, a peak force is observed and post-peak softening occurs. A higher rate of destructuration reduces the peak pullout capacity and also causes a sharper post-peak reduction in load. However, this only has a limited effect on the pullout capacity factor. As evident in Fig 6d, the rate of destructuration does not have such a major influence on the normalised capacity as the degree of initial structure.

No post-peak softening is observed at this depth for vented anchors (Fig. 7) because the ultimate load, which is attained when the failure mechanism reaches the surface, is not reached for a displacement of $0.5 B$. The relationship between pullout capacity and the degree of initial structure (Figs. 7a and 7b) is similar to the attached interface condition. In this case, the clay structure delays the reduction in stiffness due to the development of plastic strains. As structure is lost, the load-displacement curve reduces to the same shape as the remoulded clay but at a higher load. Again, a higher initial degree of structure tends to reduce the $N_{c}$ value. Figs $7 \mathrm{c}$ and $7 \mathrm{~d}$ show that increasing the rate of destructuration results in a lower pullout capacity, but the effect on the capacity factor is minimal once destructuration occurs $(k>0)$.

In the two analysis cases where softening does not occur, in remoulded clay $\left(r_{0}=1\right)$ and clay 

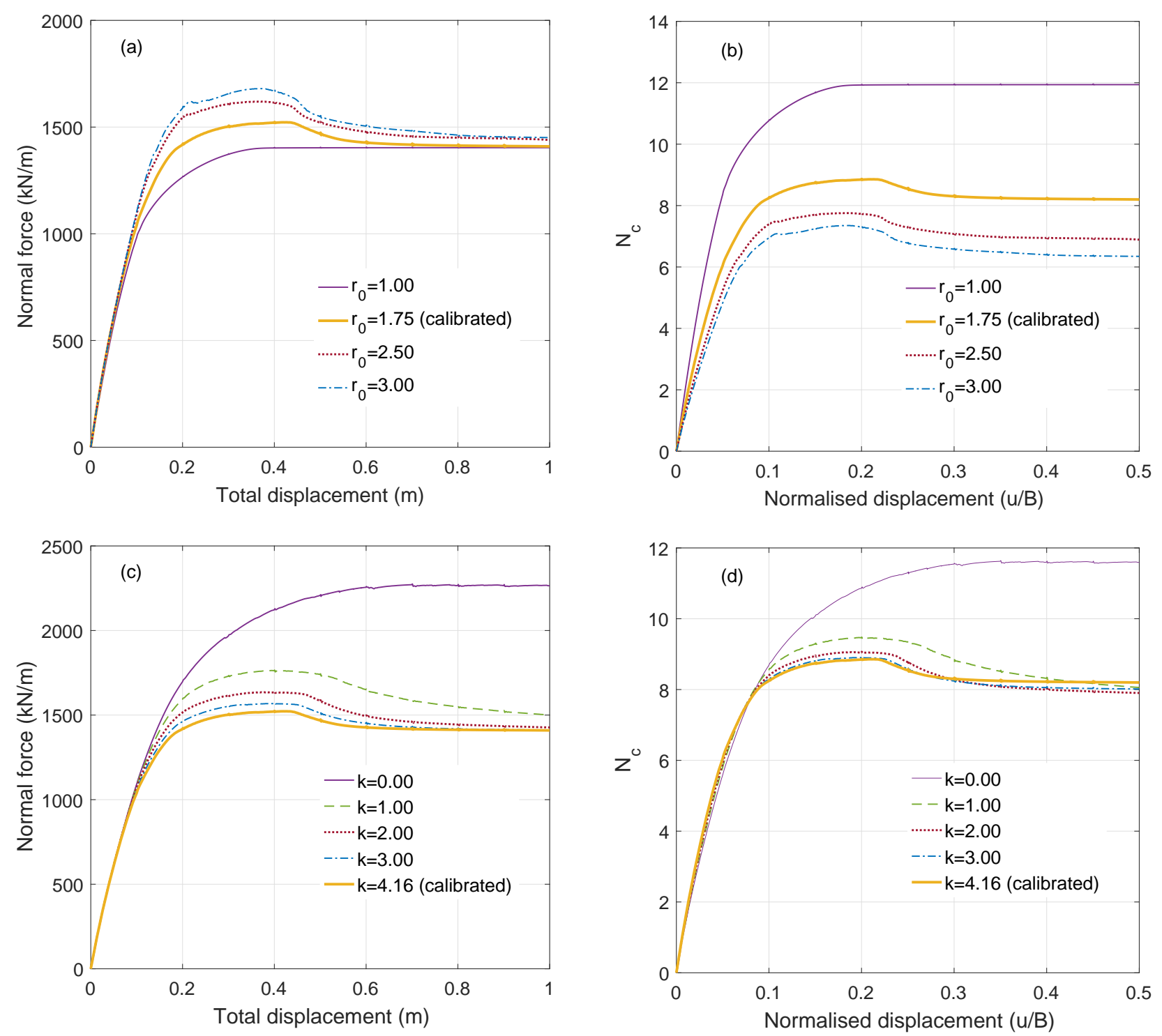

Figure 6: Effect of (a-b) initial degree of structure $\left(r_{0}\right)$ and $(c-d)$ rate of destructuration $(k)$ on load-displacement curves and pullout capacity factor for a deep, attached anchor $(H / B=10)$. 
with constant structure $(k=0)$, very similar values of Nc are obtained: 12.0 (11.6) in attached conditions and 5.2 (4.9) in vented conditions for the corresponding cases $r_{0}=1(k=0)$. The non-softening capacity factors can be compared to previous studies that used simple perfectlyplastic models to represent clay behaviour. For clay with constant structure $(k=0)$, the position of the structure surface actually causes an overconsolidated response and so the MCC model will be used for comparison as a normally consolidated clay is of interest here. In the following section the pullout capacity factor in structured Norrköping clay will be compared with the non-softening capacity factors from the MCC model and other results reported in the literature.
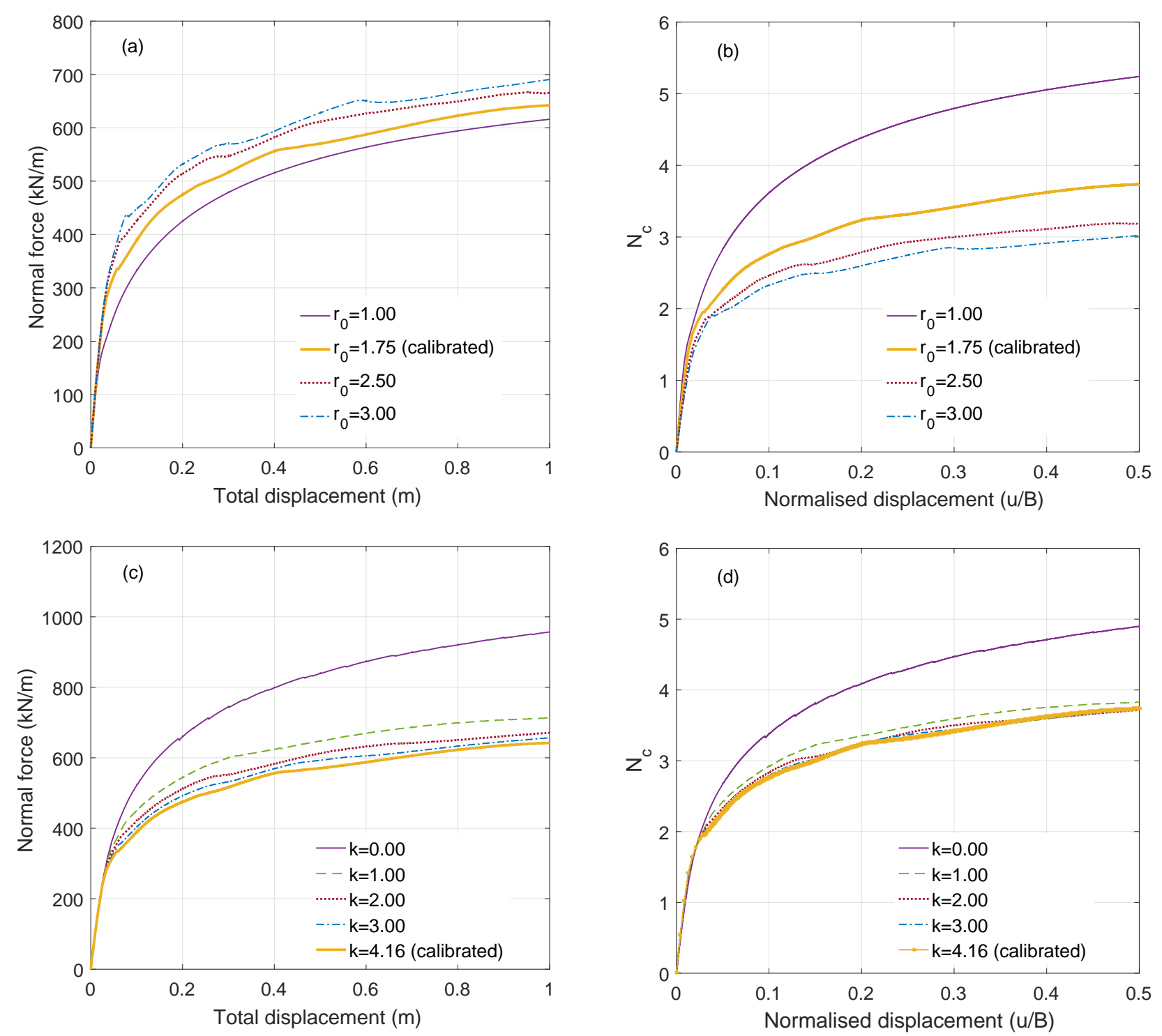

Figure 7: Effect of (a-b) initial degree of structure $\left(r_{0}\right)$ and (c-d) rate of destructuration $(k)$ on load-displacement curves and pullout capacity factor for a vented anchor $(H / B=10)$. 


\subsubsection{Pullout capacity factor}

The pullout capacity factors for horizontal anchors in non-softening clay (using an MCC model) and structured clay are shown in Fig. 8, for a range of $H / B$ ratios. The $s_{u}$ profiles used to normalise the pullout force were presented in Fig. 3, with strength gradients of $2.94 \mathrm{kPa} / \mathrm{m}$ and $4.30 \mathrm{kPa} / \mathrm{m}$ for non-softening and structured clay respectively. Previous finite element results for uniform, elastic-perfectly plastic clays reported by Yu et al. [13] and Rowe and Davis [6] are also shown, in addition to plasticity solutions by Merifield et al. [7] for vented anchors. Although the combined influence of clay weight, strength gradient, and different failure criterions (in the vented interface condition) make comparison difficult, it is reasonable to compare the limiting $N_{c}$ value $\left(N_{c_{\max }}\right)$ for deep, attached anchors, for which the upper bound plasticity solution is 11.42 [6]. The $N_{c_{\max }}$ of non-softening clay in the current study is slightly overestimated $\left(N_{c_{\max }}=12.0\right)$ but shows a relatively good fit with values obtained in previous numerical analyses. The bounding solutions for vented anchors, obtained for a uniform strength profile, are rather higher than the results of the non-softening analysis. This may be attributed to failure being defined at a specified displacement for vented anchors, as the general trend of increasing $N_{c}$ with embedment depth is captured but at a shallower gradient due to the failure mechanism not being allowed to fully develop.

Fig. 8 shows that the pullout capacity factor in non-softening clay is higher than that in structured clay across all embedment ratios, suggesting that values of $N_{c}$ obtained by conventional non-softening analyses may be overestimating capacity in natural clays. This also reflects the conclusions of other studies of embedded objects in strain-softening clays, such as penetrometers [22, 23] and spudcans [24], where values of normalised capacity were found to be lower if softening behaviour is taken into account. In Norrköping clay, the ratio of structured to nonsoftening $N_{c}$ is in the range $0.71-0.76$ for attached anchors and $0.68-0.76$ for the vented interface condition. The clay structure does not influence the critical embedment ratio, marking the transition from a shallow to deep anchor, implying that displacement mechanisms are similar for anchors in structured and non-softening clays.

In practice, the installation process of the SEPLA will cause remoulding to occur. Local structure degradation will also result from plastic deformation during keying [9]. Some degree of structure will remain following installation of the plate anchor but it is unlikely to be fully intact across the soil domain, nor will it be completely lost. The lower bound of the capacity factor post-installation can be taken as the residual value of $N_{c}$ in the structured clay, after complete remoulding has occurred along the failure planes. As an example, the reduction from peak to residual strength represents an $8 \%$ loss of capacity for an anchor at $H / B=10$ (Fig. $6 \mathrm{~b}$ 


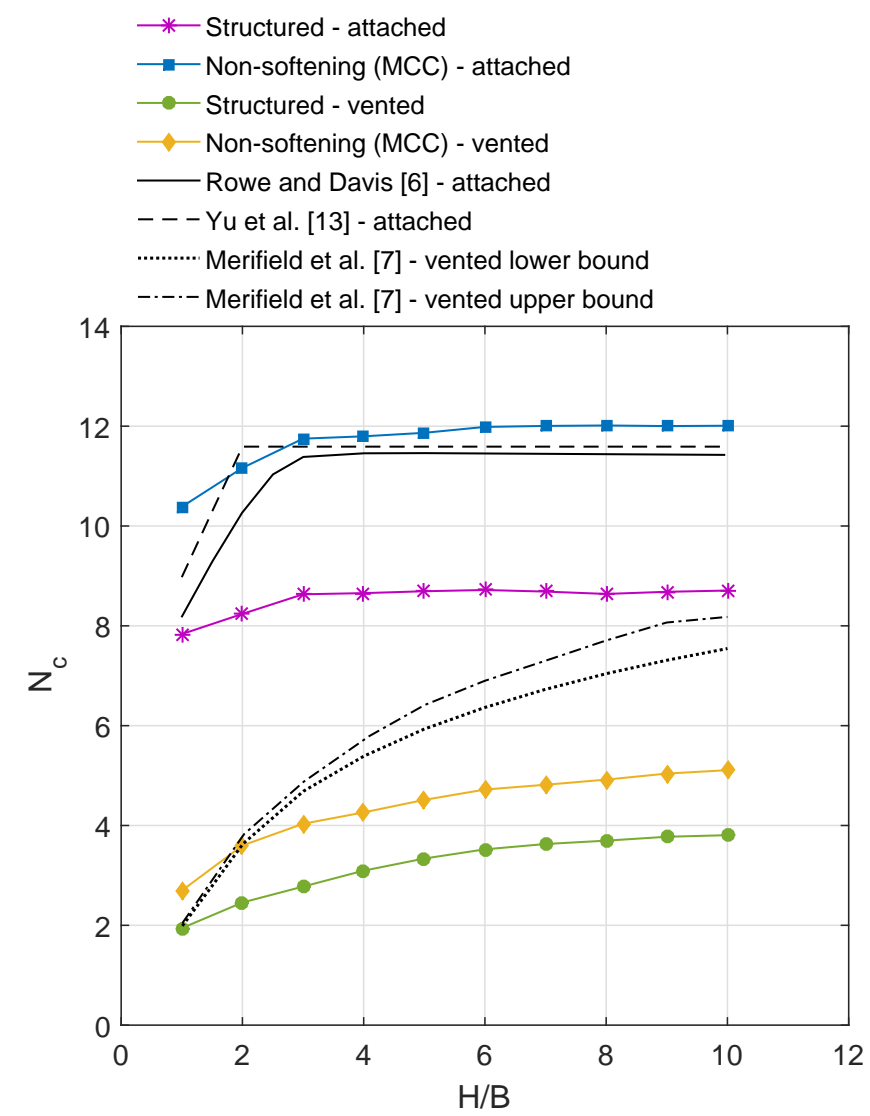

Figure 8: Pullout capacity factors for horizontal anchors. 
$\left.r_{0}=1.75\right)$. Across all embedment ratios, this reduction is in the range $5-10 \%$. For a vented anchor, a similar lower bound can be calculated if the force obtained in the remoulded clay is normalised by the peak shear strength in structured clay (in order to overcome the truncated simulation). In this case, the maximum reduction in $N_{c}$ is $10 \%$.

\subsection{Pullout capacity of inclined plate anchors in structured clay}

Fig. 9 shows the pullout capacity factors for attached anchors at a range of post-keying inclinations $\left(\beta=0^{\circ}, 22.5^{\circ}, 45^{\circ}, 67.5^{\circ}, 90^{\circ}\right)$. It can be seen that all cases tend towards a maximum capacity factor of around 8.7. The effect on pullout capacity of anchor inclination is relatively insignificant for embedment ratios greater than 4. At shallow embedment ratios, a horizontal anchor has the highest pullout capacity, and capacity reduces with increasing inclination. The critical embedment ratio is also seen to increase as the anchor is more steeply inclined; the plastic flow becomes localised at a greater depth. In a normally consolidated clay, there is still capacity to be gained from an embedment beyond this critical point due to the increasing strength profile with depth. However after the critical depth is reached the maximum pullout force must increase in a manner directly proportional to shear strength, so the rate of gain in capacity is reduced.

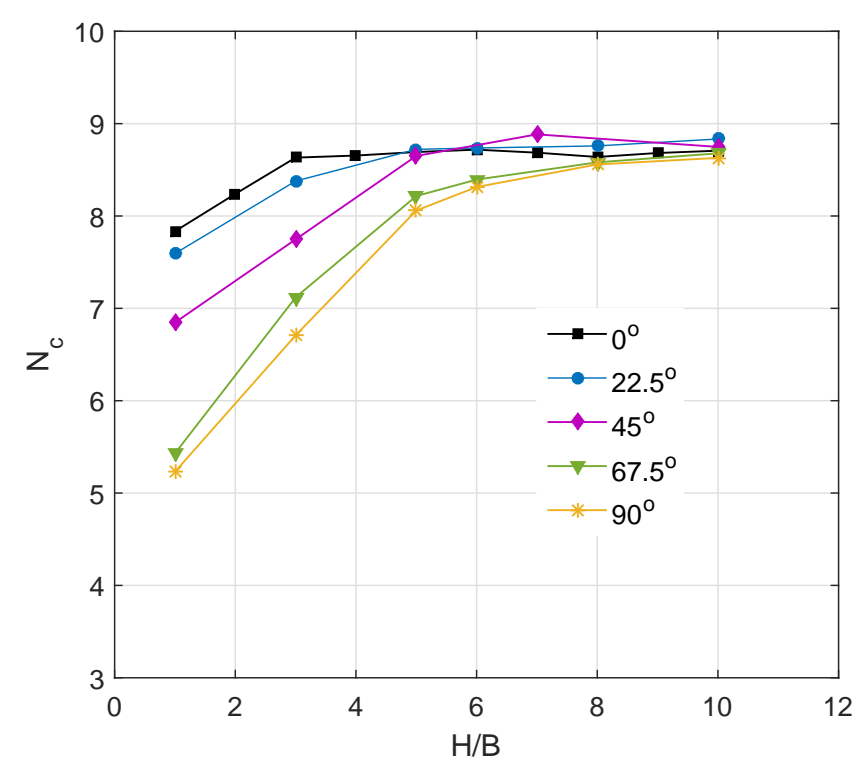

Figure 9: Pullout capacity factors for attached anchors at a range of inclinations.

For vented anchors, inclination has a profound effect upon the pullout capacity factor for all depths, as is evident in Fig. 10. The vertical anchor $\left(\beta=90^{\circ}\right)$ gives the highest factor, with capacity reducing for less steep inclinations. This is in direct contrast to behaviour if the anchor and soil are attached, as the greatest pullout capacity was found in the horizontal case. The 
contrasting relationship between $N_{c}$ and anchor inclination for different interface conditions reflects the results of Yu et al. [13] for a uniform, weightless clay. Although Yu et al. [13] found that the capacity became constant as the inclination reduced below $45^{\circ}$, here a relatively constant difference is observed between each inclination angle. This may be a consequence of the use of a practical failure criterion.

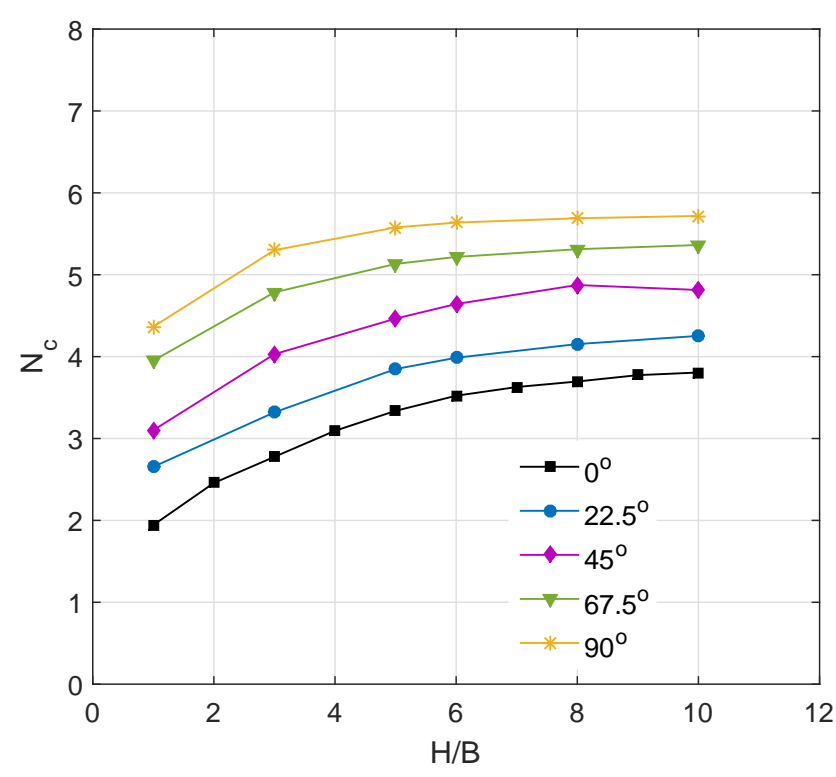

Figure 10: Pullout capacity factors for vented anchors.

The difference in behaviour between the attached and vented case may be explained by observing the failure mechanism in each interface condition, as illustrated in Fig. 11 for the case $H / B=2$. For a horizontal anchor, if the soil and anchor are fully bonded together (11a) the shear zone extends a distance beneath the anchor, in both horizontal directions. If soil and anchor detach, shown in $11 \mathrm{~b}$, the failure plane runs immediately upwards and increases in width as weaker soil is activated. The greater length of the shear plane in the attached case, coupled with the activation of stronger soil at depth, adds significantly to the resistance.

For vertical anchors, in the attached case the soil engaged behind the anchor does not benefit from the increase in shear strength with depth seen in the horizontal case. The failure plane is much shorter and consequently the vertical anchor has a lower pullout capacity. The inclinations $\left(22.5^{\circ}, 45^{\circ}\right.$ and $\left.67.5^{\circ}\right)$ are intermediate steps; the failure plane tends to shorten and less soil is activated beneath the anchor, lowering the pullout capacity factor. In the vented case the increased pullout capacity for vertical anchors is explained by the failure mechanism extending deeper into the soil compared to the horizontal case. Again, the intermediate inclinations show the engagement of greater regions of deeper, stronger soil in the shear zone. 
Fig. 12 shows failure mechanisms for deep, horizontal anchors. The localisation of plastic flow is immediately evident for the attached anchor. It may be noticed that plastic deformation extends further above the anchor than below due to the linearly increasing shear strength profile. Failure mechanisms for attached anchors at other inclinations follow the same pattern: instead of the mechanism reaching the ground surface, plastic deformation is localised at the anchor.

For illustration purposes, Fig. 12b presents a vented anchor at the same embedment ratio $(H / B=4)$. The failure mechanism is essentially the same as that shown in Fig. 12 for a shallower embedment, hence the lack of a critical embedment ratio in vented cases. As noted by Song et al. [8], if the overburden pressure to shear strength ratio was high enough, an attached mechanism would form. A truncated failure criterion has been used in this study and the ultimate pullout load would not be attained until the failure mechanism reaches the surface.

\subsection{Degradation of structure during pullout}

The KHSM also allows observation of the loss of clay structure as an anchor is loaded to failure. Fig. 13 shows the loss of structure around a deep anchor $(H / B=10)$ at displacements of $0.05 B, 0.1 B$ and $0.2 B$, when the failure mechanism is fully developed. The destructuration strain parameter A, determining the contribution to structure degradation from volumetric and shear strain, is 0.494 and so almost equal contributions from the two strain components would be expected. However, in undrained conditions plastic volumetric strain is necessarily small and the loss of structure is therefore primarily caused by shear strain.

After a displacement of $0.05 B$, in both interface scenarios a total loss of structure has occurred in isolated regions at the tips of the anchor. The difference between attached and vented conditions is immediately apparent. The loss of structure extends above and below the attached anchor in a similar manner. In the vented case, only a limited amount of localised degradation is observed beneath the anchor. No tension is allowed in the vented interface and the loss of structure below the anchor is likely due to the effect of overburden pressure. At this displacement, structure loss is more extensive in the vented case, suggesting the failure mechanism is quicker to develop.

The two zones of remoulded clay at the anchor tips continue to grow as plastic shear strains accumulate and at $0.1 \mathrm{~B}$ displacement have converged at a central location above the anchor. It is interesting to note that a zone of relatively intact structure remains above the anchor. At this stage, in the attached case regions of remoulded clay extend downwards from the anchor tips as the fully localised failure mechanism develops. At $0.2 B$ displacement this mechanism is fully formed, and the anchor is enveloped in a zone of remoulded soil, aside from isolated regions 


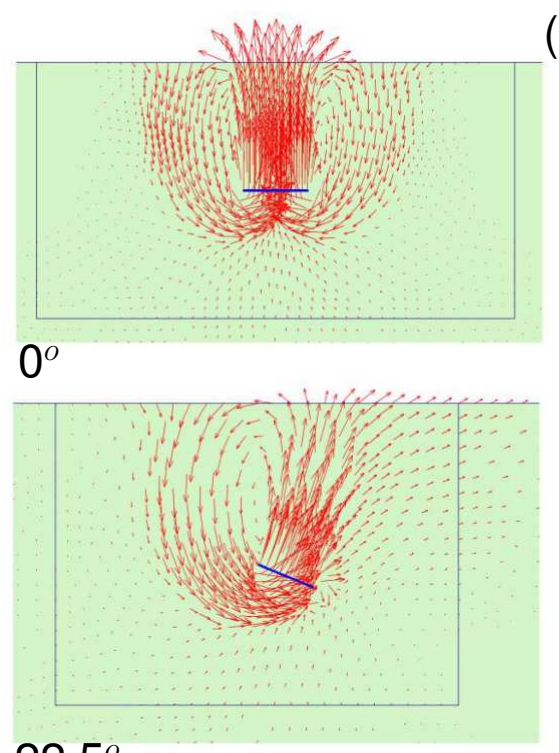

(a)

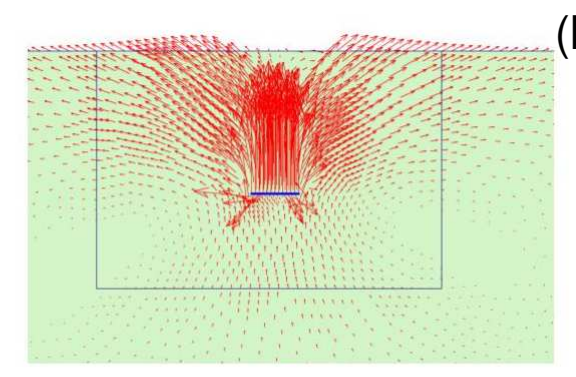

(b)
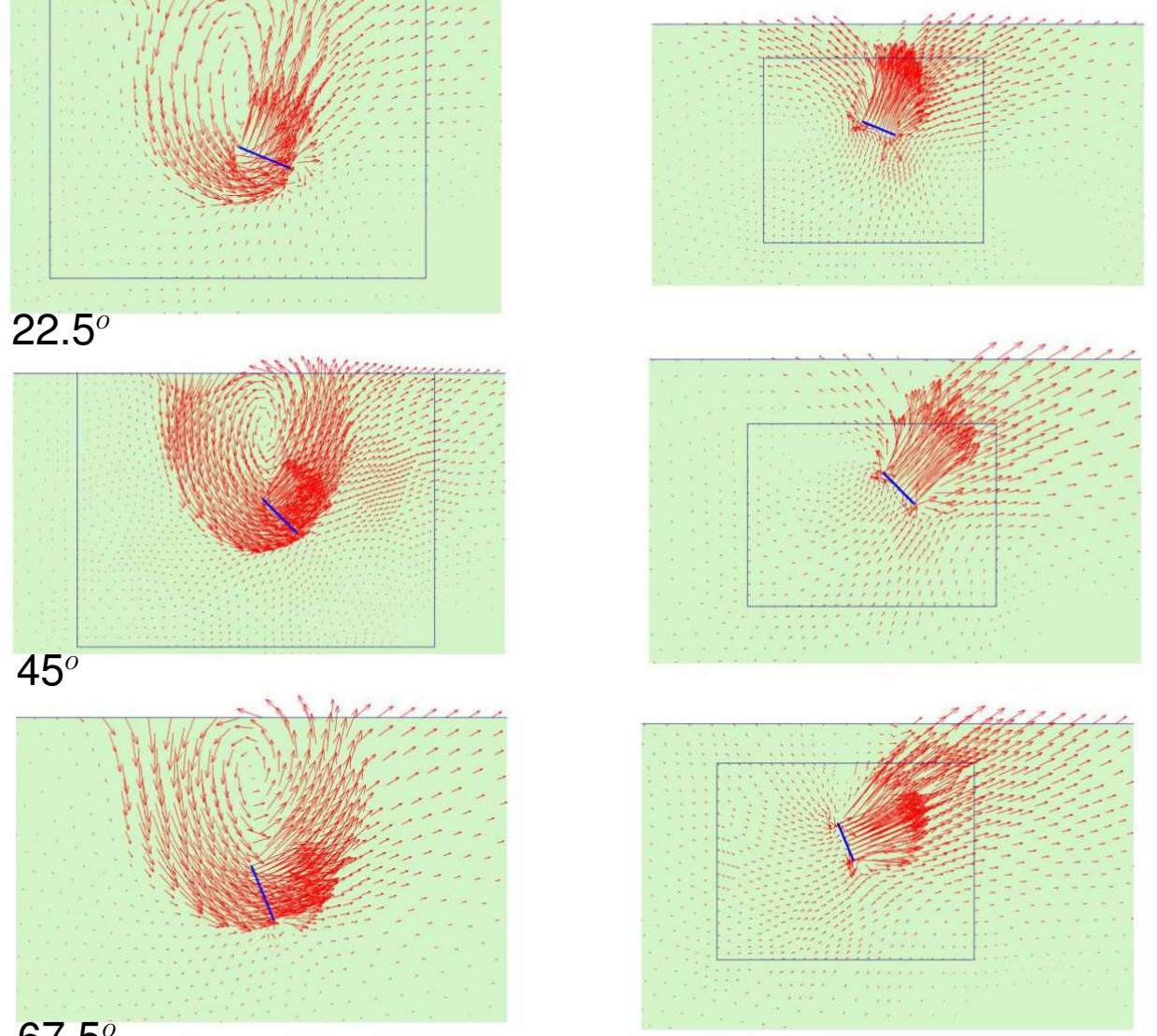

$67.5^{\circ}$
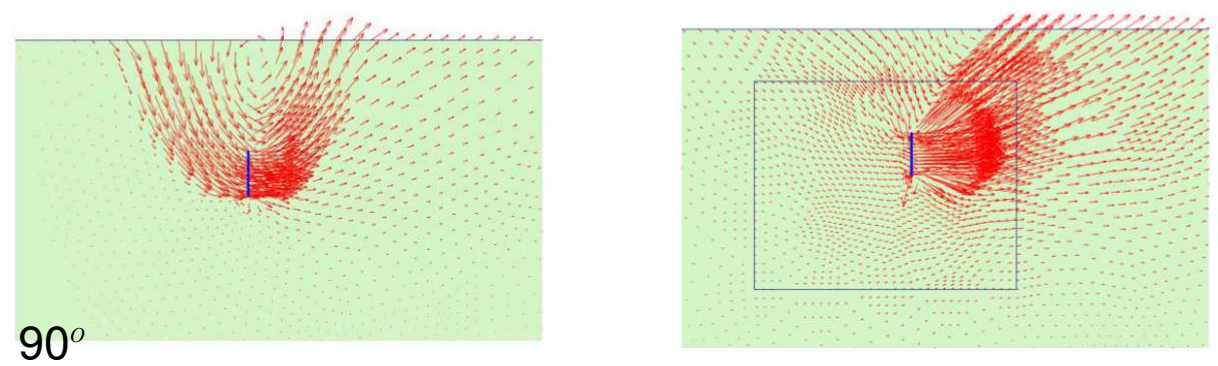

Figure 11: Displacement vectors at failure at inclination angles from $0^{\circ}$ to $90^{\circ}$ for (a) attached and (b) vented anchors $(H / B=2)$. 
(a)

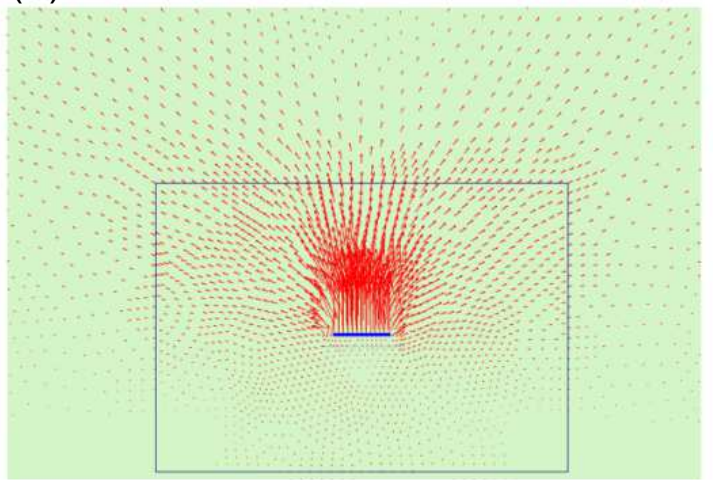

(b)

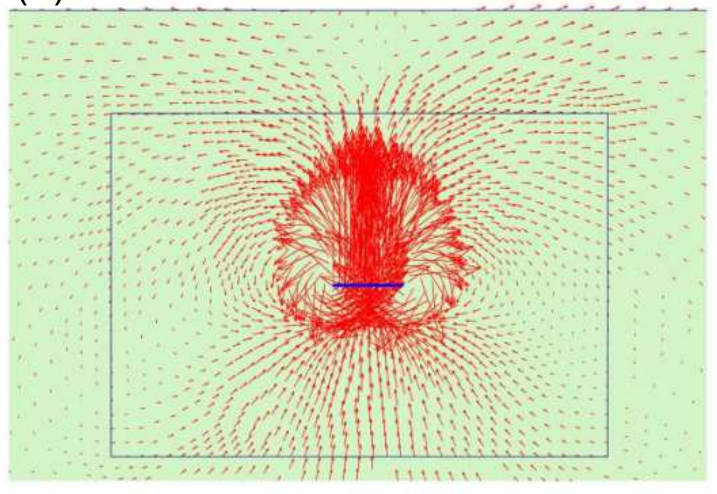

Figure 12: Displacement vectors at failure for a) attached and b) vented anchors $(H / B=4)$.

next to the anchor. In contrast structure continues to degrade only above the vented anchor, as the failure mechanism progresses towards the surface.

A pullout load has a similar effect on clay structure if the anchor is inclined. The loss of structure follows the development of plastic shear strains in the soil as the failure mechanism forms. An interesting case occurs when the effect of anchor inclination on the critical embedment ratio is considered. As observed in Section 6.1.2, anchor inclination can change the critical ratio from $H / B=3$ (horizontal anchor, $\beta=0^{\circ}$ ) to $H / B=8\left(\right.$ vertical anchor, $\beta=90^{\circ}$ ).

Fig. 14 presents the illustrative case $H / B=5$ for anchor inclinations $0^{\circ}, 45^{\circ}$ and $90^{\circ}$. At this embedment ratio, loss of structure is localised around the horizontal anchor, which deforms according to a deep failure mechanism as described previously. If the anchor is inclined at $45^{\circ}$, the loss of structure is less localised. It is clear that limited plastic shear strains must reach the surface as a zone of substantial but not total loss of structure is observed. This reflects the fact that, as may be concluded from Fig. 8 , for $\beta=45^{\circ}, H / B=5$ is the critical embedment ratio. The majority of the plastic flow, and associated loss of structure, occurs around the anchor and the proximity of the ground surface does not affect the pullout capacity factor. For a vertical anchor, structure degradation clearly extends away from the anchor into the soil mass. The 
(a) Attached

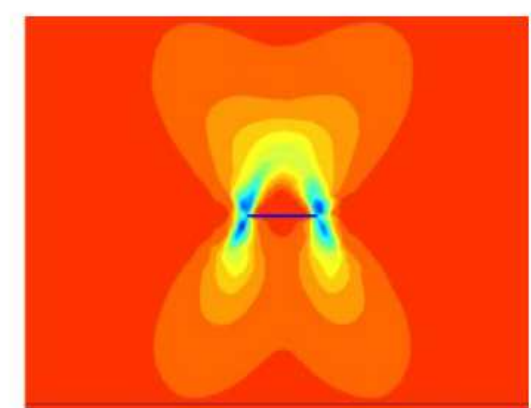

$\mathrm{u}=0.05 \mathrm{~B}$

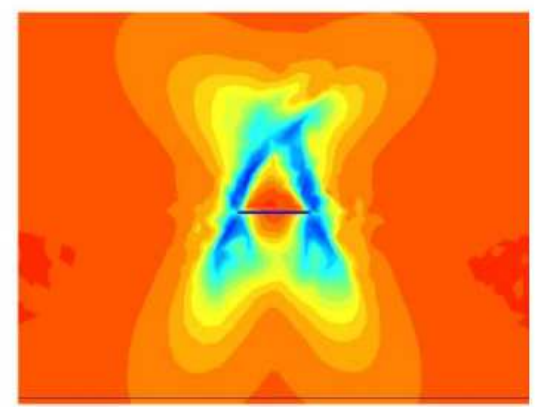

$\mathrm{u}=0.1 \mathrm{~B}$

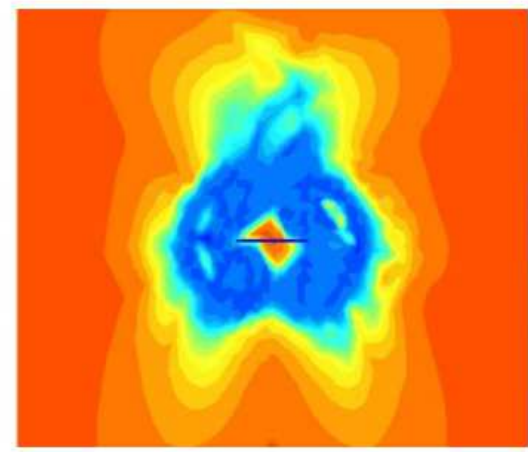

$\mathrm{u}=0.20 \mathrm{~B}$ (b) Vented

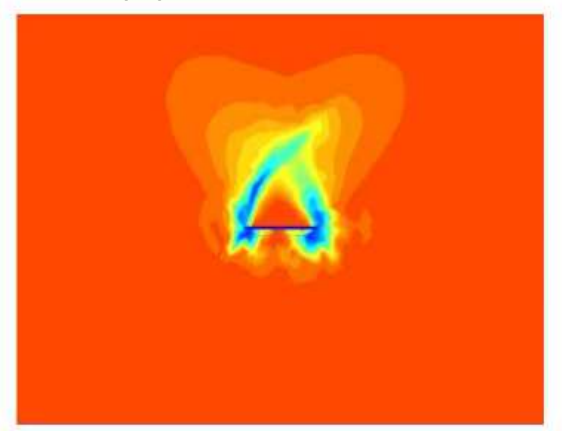

Structure $r$

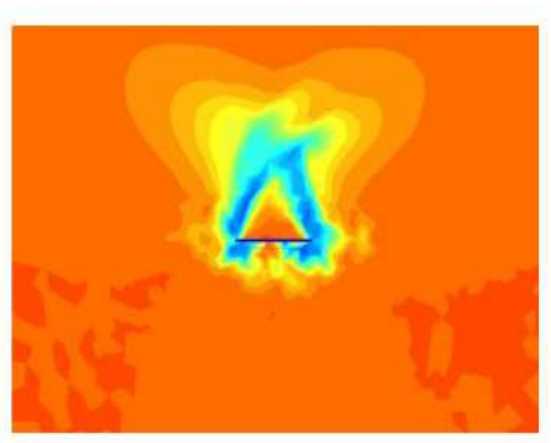

1.75

1.70

1.65

1.60

1.55

$-1.50$

$-1.45$

1.40

1.35

1.30

1.25

1.20

1.15

1.10

1.05

1.00

Figure 13: Loss of structure at different displacements for a) attached and b) vented anchor $(H / B=10)$. 
failure mechanism reaches the ground surface and the anchor is classified as shallow.

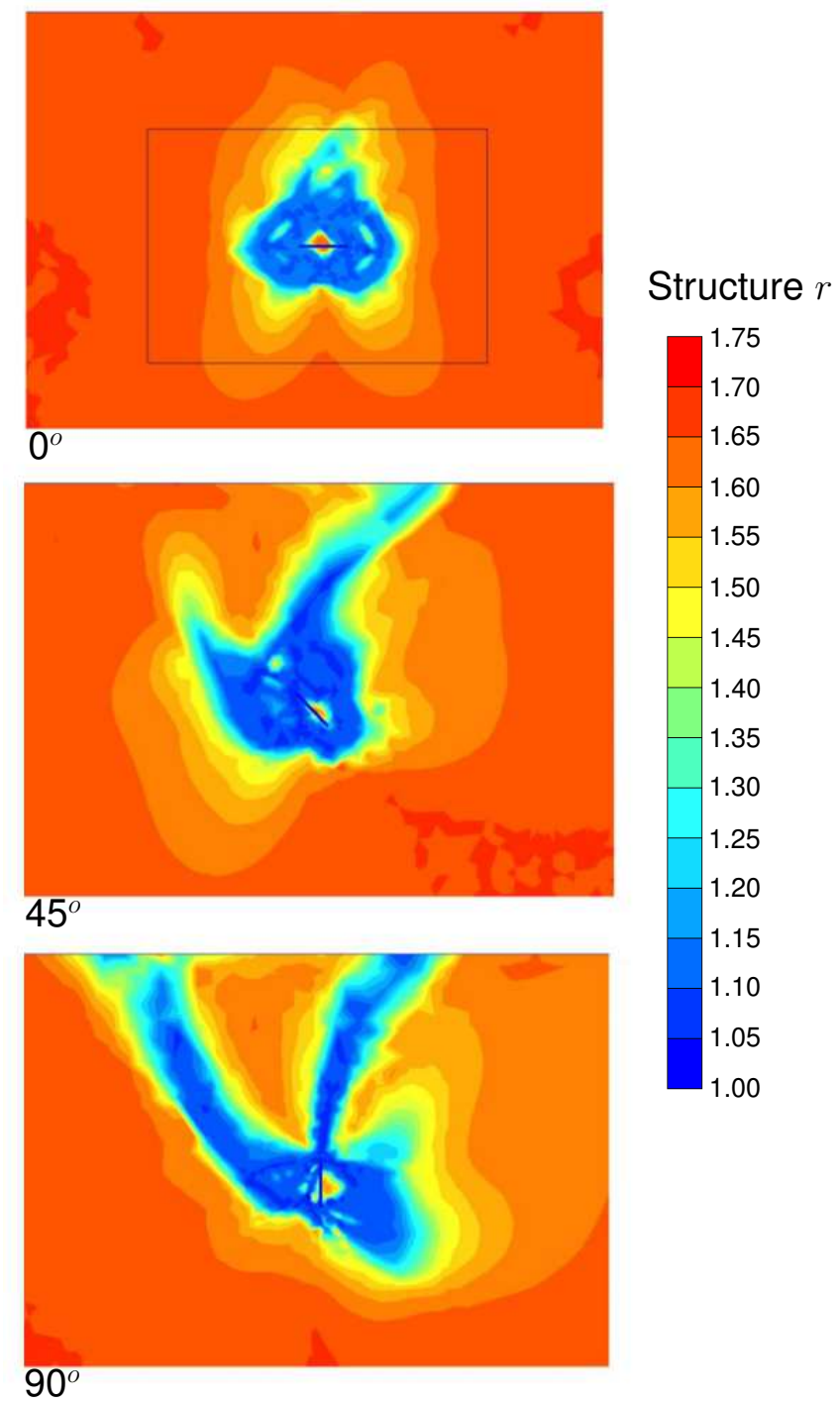

Figure 14: Loss of structure at failure for inclined attached anchors $(H / B=5)$.

\section{Conclusions}

In this paper a finite element analysis of the pullout capacity of SEPLAs in a structured clay has been conducted. An advanced kinematic hardening constitutive model was used to accurately describe the effect of structure on the mechanical behaviour of a plate anchor embedded in a natural clay. The degradation of clay structure is modelled as a function of plastic strain. A range of post-keying anchor inclinations have been considered and the limiting cases of an attached and vented interface were simulated.

The load-displacement relationship for attached anchors in structured clay showed a peak force followed by softening as structure is lost due to plastic strains developing along the fail- 
ure planes. The pullout force ultimately reduces to that of the remoulded clay. In terms of the pullout capacity factor, which incorporates normalisation by the peak undrained shear strength, the loss of clay structure resulted in a reduction in capacity factor compared to non-softening clay. The ratio of structured to non-softening capacity factor for vented and attached conditions was in the range $0.68-0.76$ for horizontal anchors. This suggests that values reported in previous studies may overestimate the capacity factor in natural clays as the effect of softening has not been previously accounted for in the pullout of plate anchors. A parametric study indicated that a greater degree of initial structure, corresponding to a more sensitive clay, has the effect of further reducing the pullout capacity factor. For low sensitivity clays, as considered here, it can be concluded that design capacity factors are best estimated on the basis of remoulded shear strength as the presence of initial structure offers only a relatively small increase in pullout capacity.

In undrained conditions, the loss of structure is predominantly controlled by plastic shear strains. If a pullout load is applied to an anchor in structured clay, zones of completely remoulded clay will form around the failure planes with increasing displacement. The loss of structure is more extensive for attached than for vented anchors as clay on both sides of the anchor is activated. Small regions of remoulded soil were observed beneath vented anchors, but did not extend into the soil mass.

As a final remark, it must be emphasised that the pullout capacity factors reported in this study are relevant only for the specific clay considered. Further investigation is needed into the degree of structure in the clay mass and the rate of destructuration, in addition to the effect of installation processes on the clay structure and anchor capacity.

Acknowledgment: The authors wish to thank Gerard Vallespí Català MSc for his assistance with the numerical simulations. We are also grateful to the anonymous reviewers for their constructive comments and suggestions which significantly improved the manuscript.

\section{References}

[1] EIA (US Energy Information Administration). International Energy Outlook. Washington, DC: EIA. 2013.

[2] Randolph MF, Gaudin C, Gourvenec SM, White DJ, Boylan N, Cassidy MJ. Recent advances in offshore geotechnics for deep water oil and gas developments. Ocean Eng 2011; 38(7): 818-834. 
[3] Wilde B, Treu H, Fulton T. Field Testing of Suction Embedded Plate Anchors. Proceedings of the 11th Int Offshore and Polar Engineering Conference. Stavanger, Norway, June 17$22,2001$.

[4] Vesic AS. Breakout Resistance of Objects Embedded in Ocean Bottom. J Soil Mech Found Div, 1971;97(9): 1183-1205.

[5] Das BM. A procedure for estimation of ultimate capacity of foundations in clay. Soils Found 1980;20(1):77-82.

[6] Rowe RK, and Davis EH. The behaviour of anchor plates in clay. Géotechnique 1982;32(1): 9-23.

[7] Merifield RS, Sloan SW, Yu HS. Stability of plate anchors in undrained clay. Géotechnique 2001;51(2): 141-153.

[8] Song Z, Hu Y, O’Loughlin, C, Randolph, MF. Loss in Anchor Embedment during Plate Anchor Keying in Clay. J Geotech Geoenviron Eng 2009; 135(10): 1475-1485.

[9] Cassidy MJ, Gaudin C, Randolph MF, Wong PC, Wang D, Tian Y. A plasticity model to assess the keying of plate anchors. Géotechnique 2012; 62(9):825-836.

[10] Das BM, Puri VK. Holding Capacity of Inclined Square Plate Anchors in Clay. Soils Found 1989; 29(3): 138-144.

[11] Meyerhof GG. Uplift resistance of inclined anchors and piles. Proc of the 8th Int Conf on Soil Mech and Found Eng. Moscow. 1073; 167-172.

[12] Merifield RS, Lyamin AV, Sloan SW. Stability of inclined strip anchors in purely cohesive soil. J Geotech Geoenviron Eng, 2005; 131(6): 792-799.

[13] Yu L, Liu J, Kong X-J, Hu Y. Numerical study on plate anchor stability in clay. Géotechnique 2011;61(3): 235-246.

[14] Tho KK, Chen Z, Leung CF, Chow YK. Pullout behaviour of plate anchor in clay with linearly increasing strength. Can Geotech J 2014; 51(1): 92-102.

[15] Wang D, Hu Y, Randolph MF. Three-Dimensional Large Deformation Finite-Element Analysis of Plate Anchors in Uniform Clay. J Geotech Geoenviron Eng, 2010;136(2):355365. 
[16] Fahmy AM, de Bruyn JR, Newson TA. Numerical Investigation of the inclined pullout behaviour of anchors embedded in clay. Geotech Geol Eng, 2013;31(5): 1525-1542.

[17] Lerouei, S, Vaughan PR. The general and congruent effects of structure in natural soils and weak rocks. Géotechnique 1990; 40(3): 467-488.

[18] Bjerrum L. Kvikkleireskred. Publication 89, Norwegian Geotechnical Institute.

[19] Det Norske Veritas. Design and Installation of Plate Anchors in Clay. DNV, Norway. 2002.

[20] Rouainia M, Muir Wood D. A kinematic hardening constitutive model for natural clays with loss of structure. Géotechnique 2000;50(2): 153-164.

[21] Roscoe KH, Burland JB. On the generalised stress-strain behaviour of wet clay. in Heyman, J. and Leckie, F.A. (eds.) Engineering plasticity. Cambridge: Cambridge University Press, 1968; 563-609.

[22] Zhou H., Randolph MF. Computational techniques and shear band development for cylindrical and spherical penetrometers in strain-softening clay. Int J Geomech 2007; 7(4): 287-295.

[23] Zhou H, Randolph MF. Resistance of full-flow penetrometers in rate-dependent and strainsoftening clay. Géotechnique 2009; 59(2): 79-86

[24] Hossain MS, Randolph MF 2009. Effect of strain rate and strain softening on the penetration resistance of spudcan foundations on clay. Int J Geomech 2009; 9(3), 122-132. 